\title{
Supplementary material for „Differences in the QBO response to stratospheric aerosol modification depending on injection strategy and species“
}

Henning Franke ${ }^{1,2}$, Ulrike Niemeier ${ }^{1}$, Daniele Visioni ${ }^{3}$

${ }^{1}$ Max Planck Institute for Meteorology, Bundesstr. 53, 20146Hamburg, Germany

${ }^{2}$ International Max Planck Research School on Earth System Modelling, Bundesstr. 53, 20146

Hamburg, Germany

${ }^{3}$ Sibley School for Mechanical and Aerospace Engineering, Cornell University, Ithaca, NY, USA

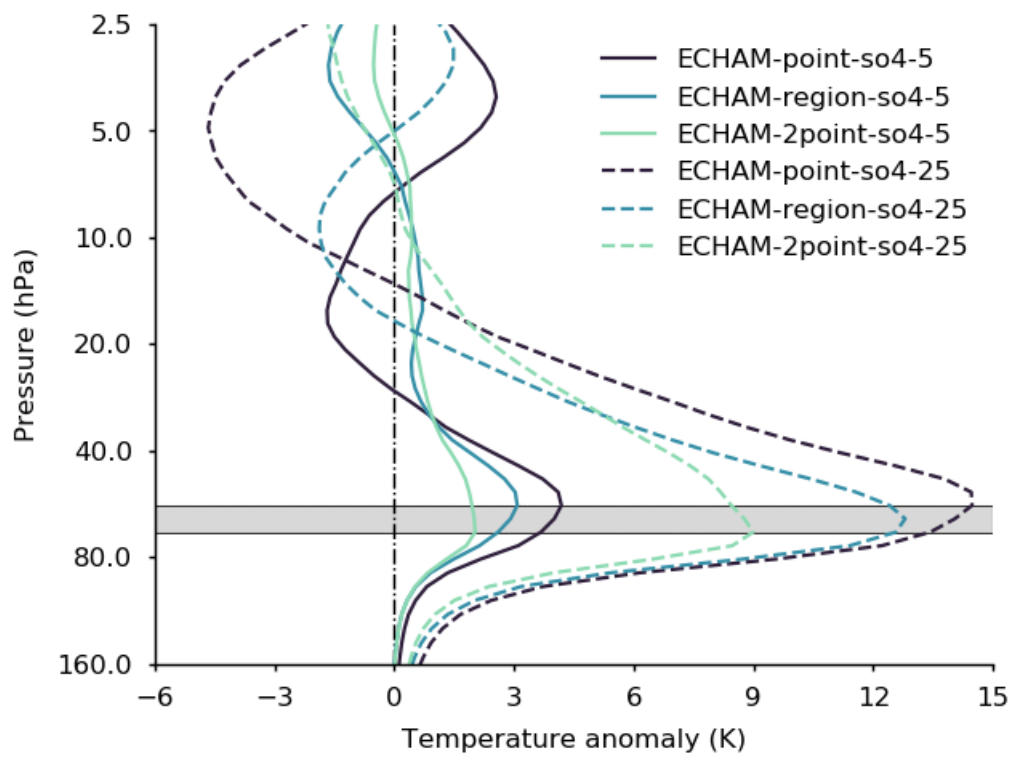

Figure S1: As Figure 4, but for the corresponding injection of $\mathrm{AM}-\mathrm{SO}_{4}$.

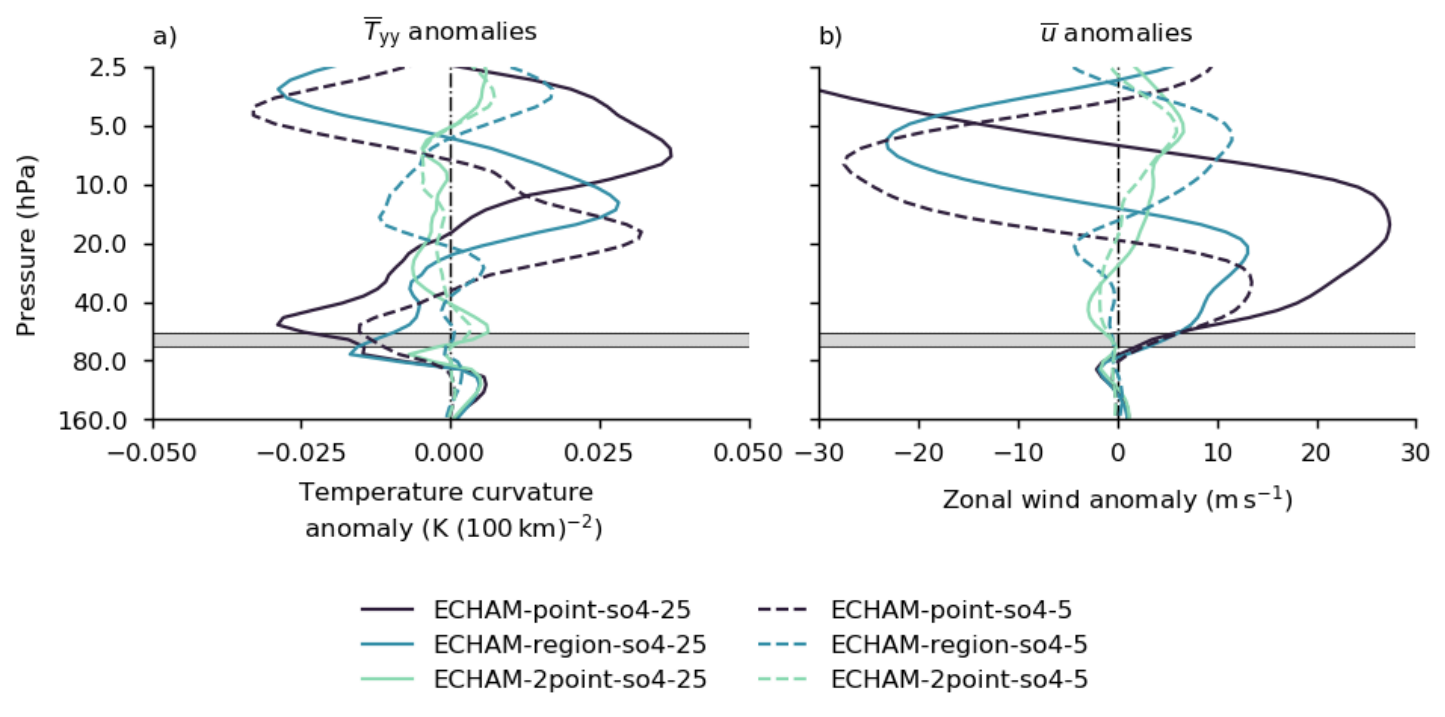

Figure S2: As Figure 6, but for the corresponding injection of $\mathrm{SO}_{2}$. 


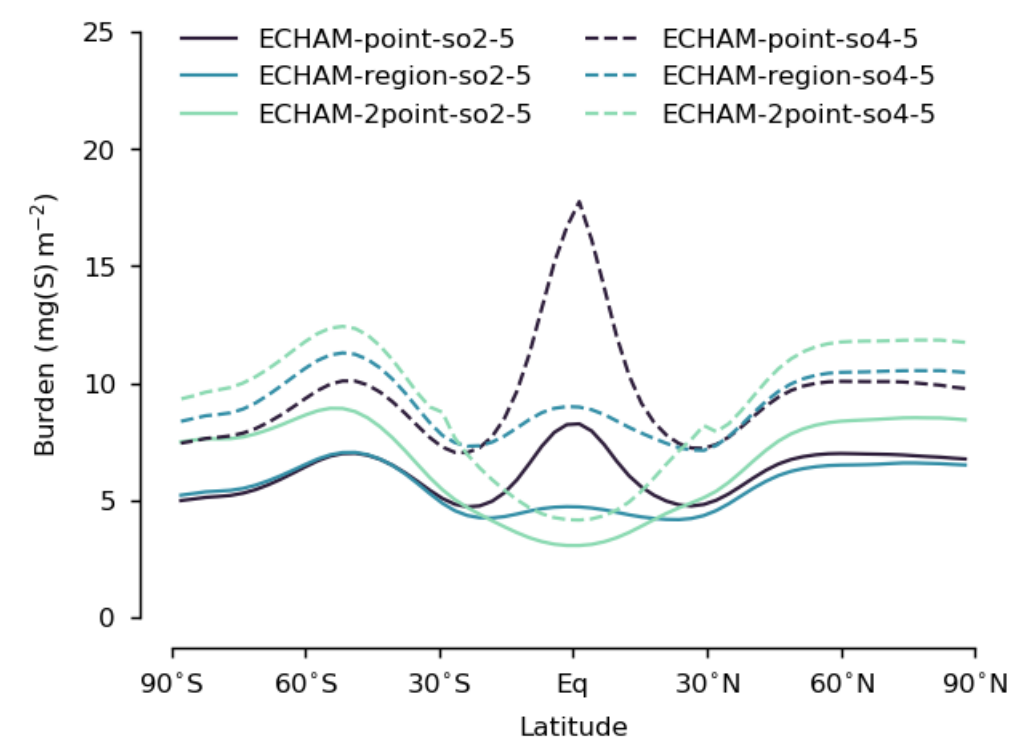

Figure S3: As Figure 7, but for the corresponding injection with an injection rate of $5 \mathrm{Tg}(S) \mathrm{yr}^{-1}$.
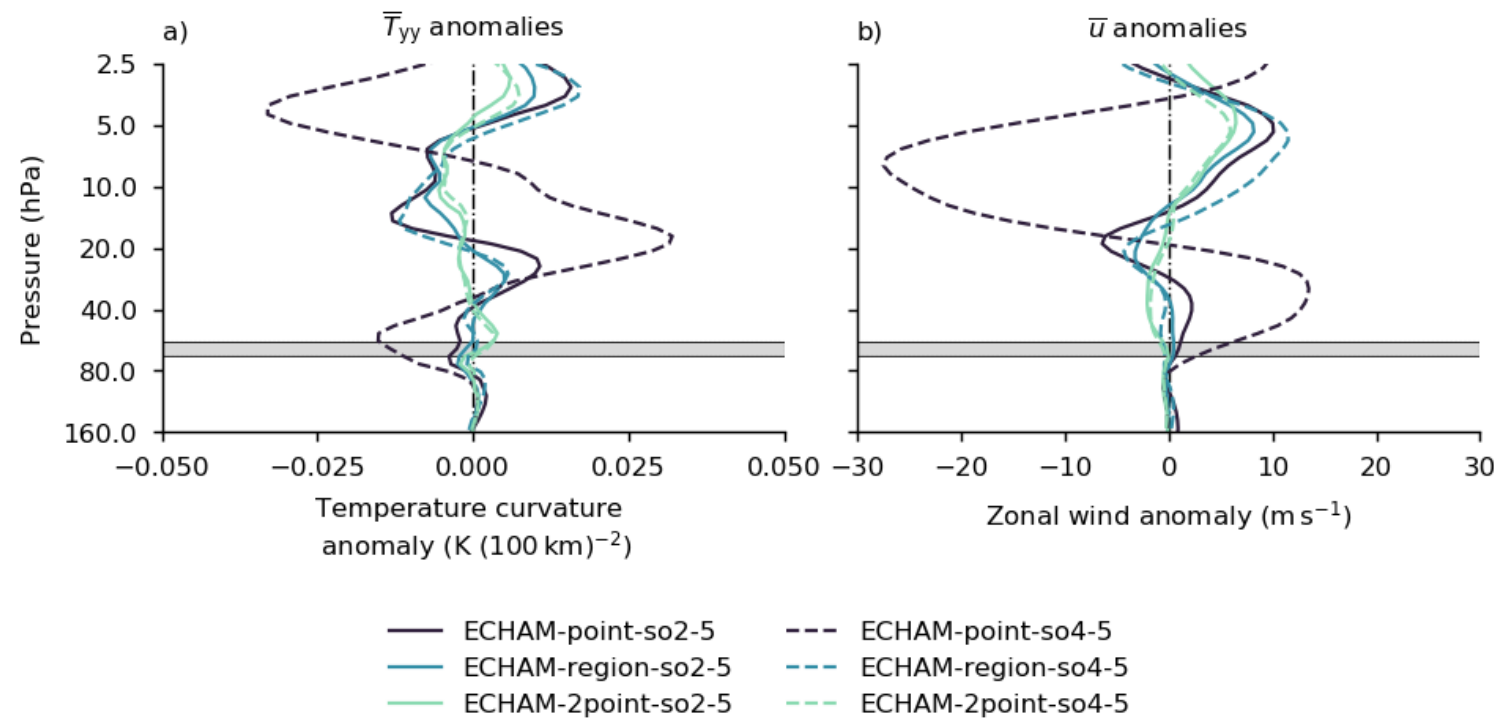

Figure S4: As Figure 8, but for the corresponding injection with an injection rate of $5 \mathrm{Tg}(\mathrm{S}) \mathrm{yr}^{-1}$. 
ECHAM

a) ECHAM-contr-000

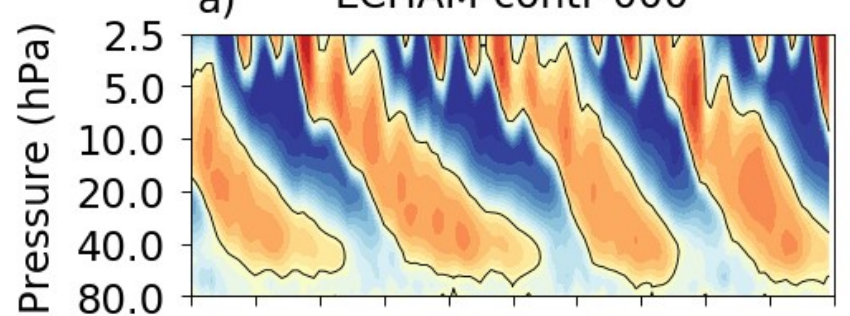

c) ECHAM-2point-so2-5

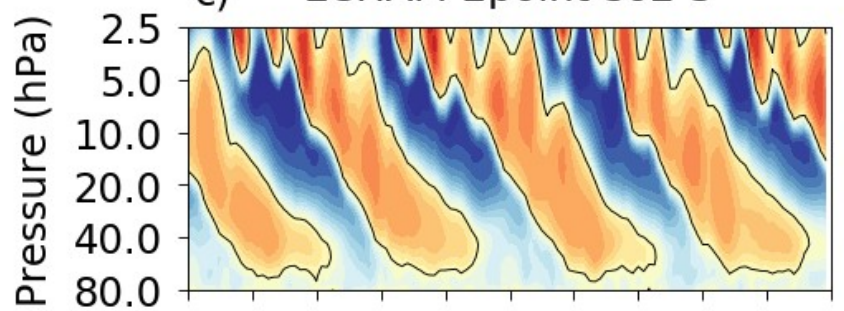

e) ECHAM-2point-so2-25
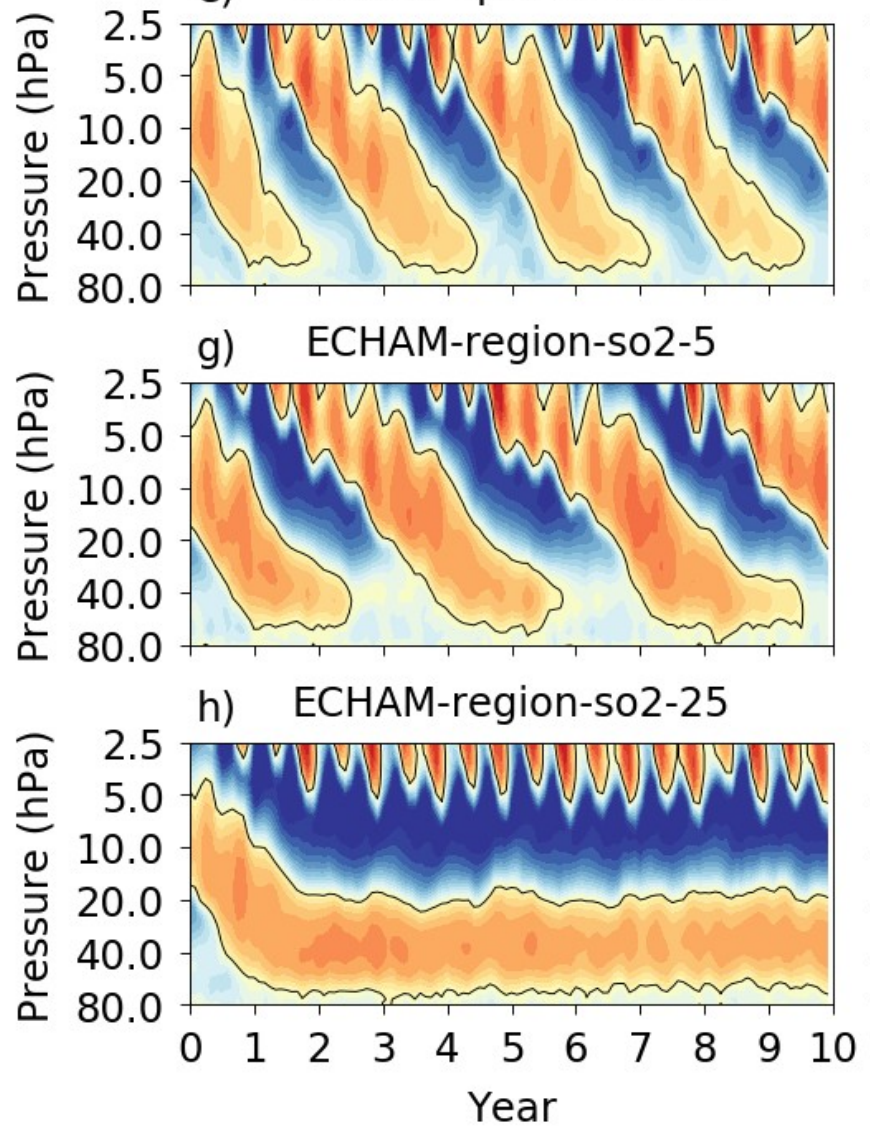

CESM

b) CESM-contr-000

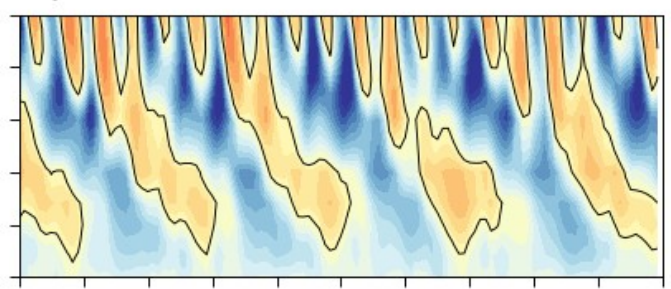

d) CESM-2point-so2-5

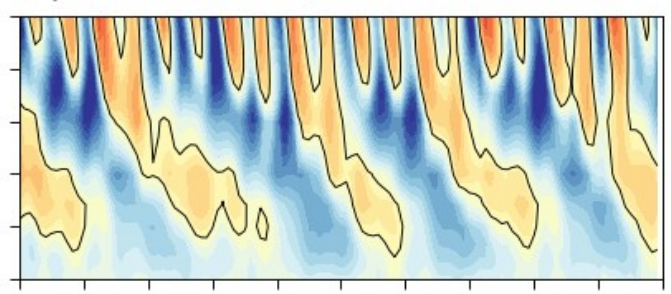

f) CESM-2point-so2-25

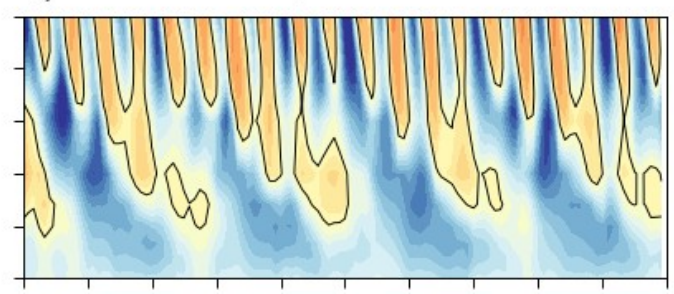

h) CESM-region-so2-5

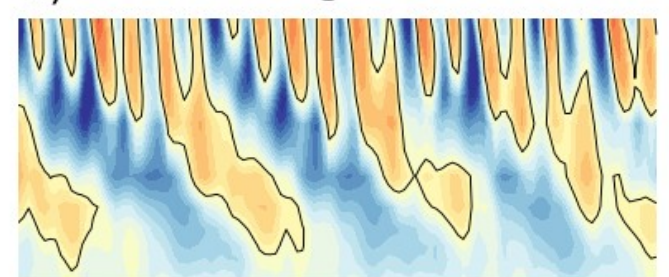

i) CESM-region-so2-25

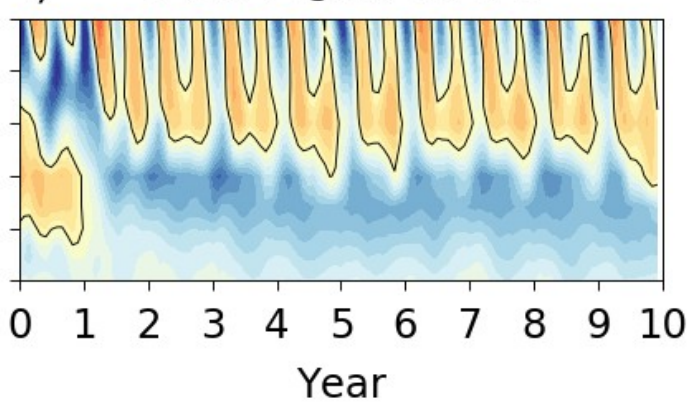

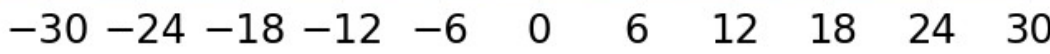

$$
\begin{aligned}
& \text { Zonal wind speed }\left(\mathrm{ms}^{-1}\right)
\end{aligned}
$$

Figure S5: As Figure 11, but for the corresponding injection of $\mathrm{SO}_{2}$. 
ECHAM

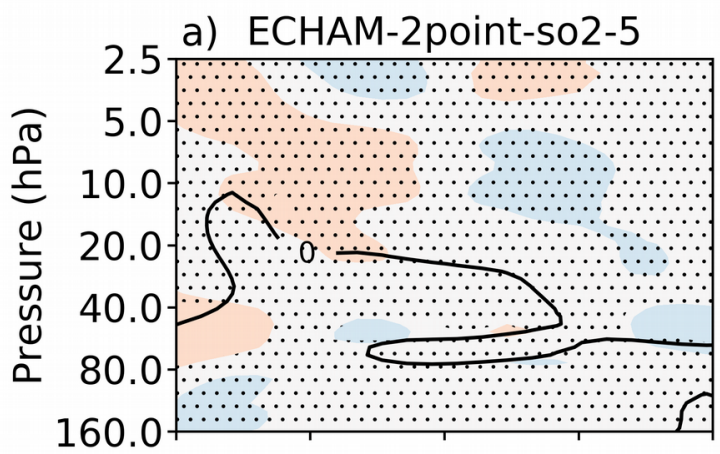

c) ECHAM-2point-so2-25
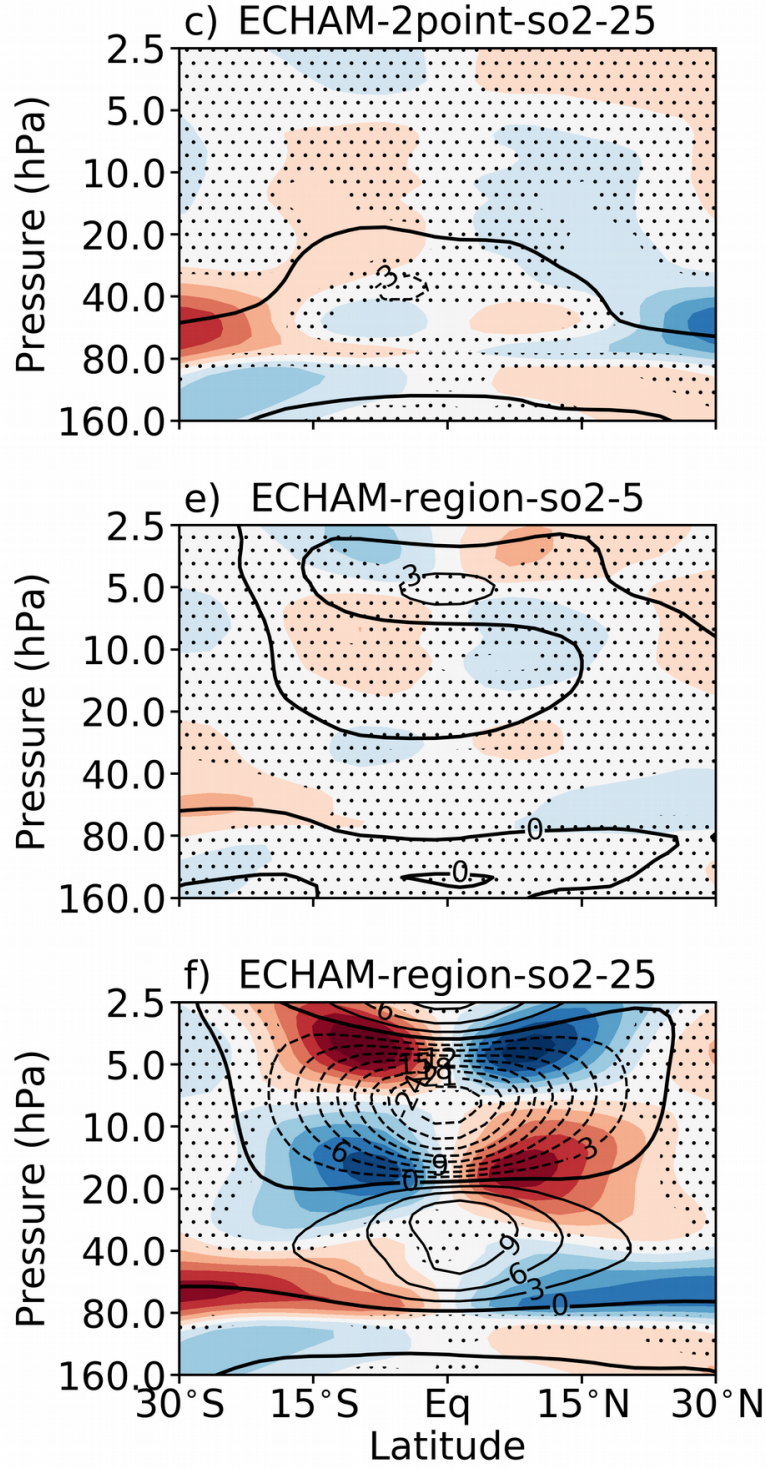

\section{CESM}

b) CESM-2point-so2-5

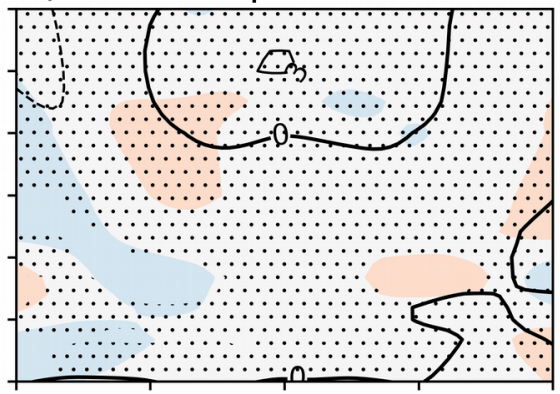

d) CESM-2point-so2-25

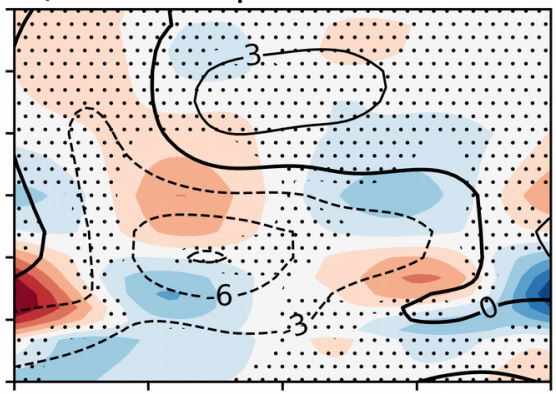

f) CESM-region-SO2-5

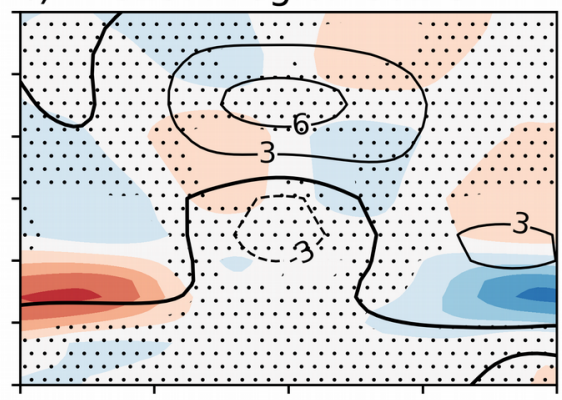

g) CESM-region-so2-25

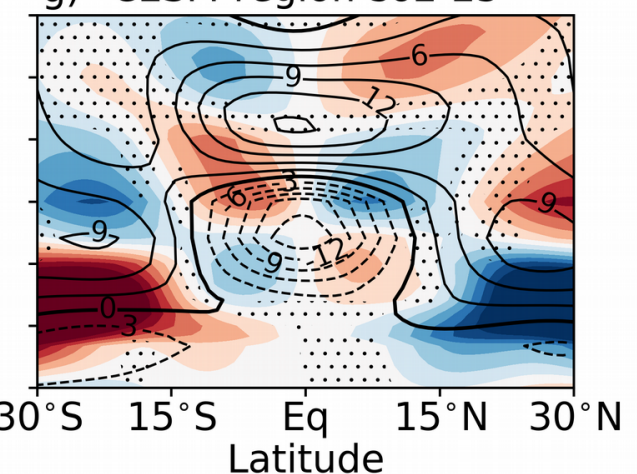

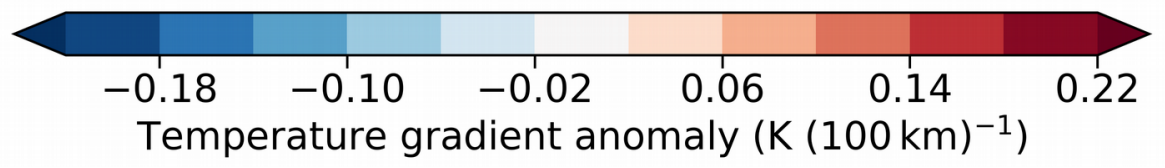

Figure S6: As Figure 12, but for the corresponding injection of $\mathrm{SO}_{2}$. 


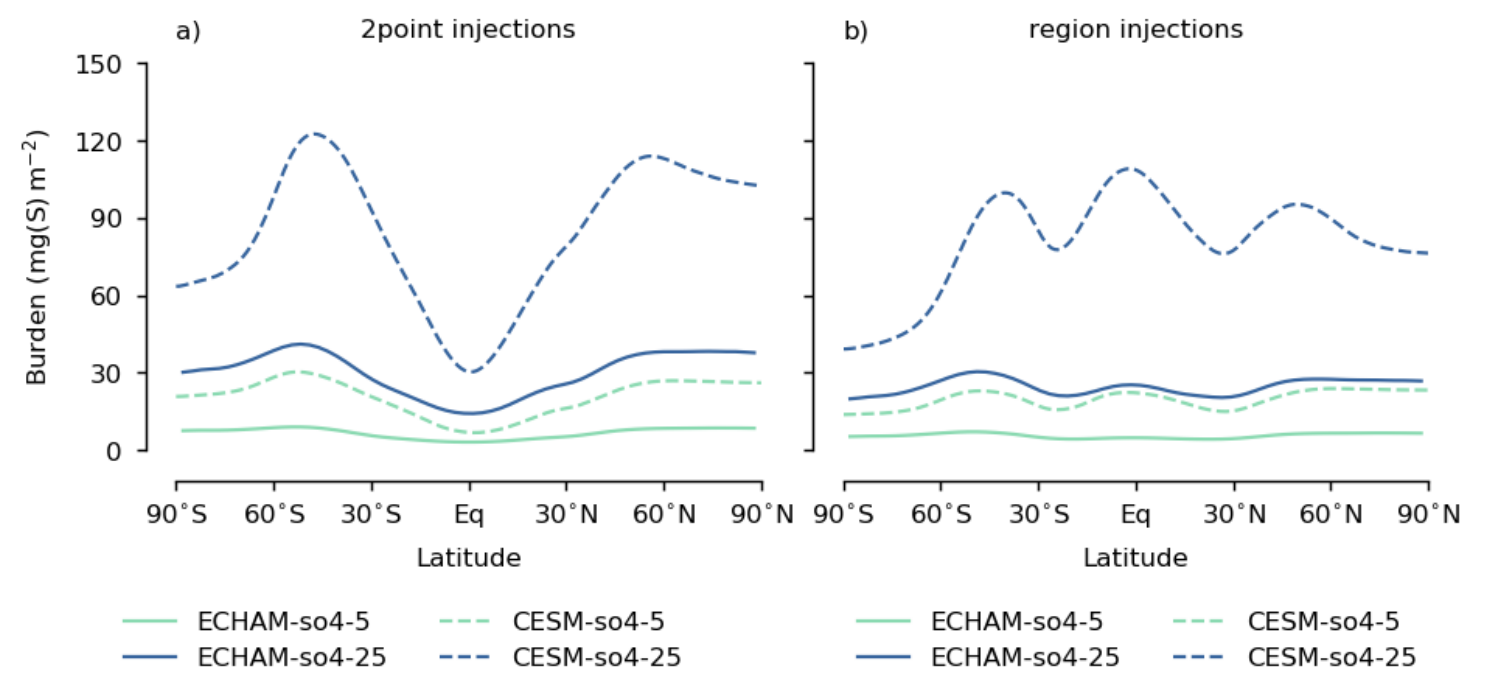

Figure S7: As Figure 13, but for the corresponding injection of $\mathrm{SO}_{2}$. 